Erratum

\title{
Erratum to "Stroke Survivors Scoring Zero on the NIH Stroke Scale Score Still Exhibit Significant Motor Impairment and Functional Limitation"
}

\author{
Brittany Hand, ${ }^{1}$ Stephen J. Page, ${ }^{2}$ and Susan White ${ }^{2}$ \\ ${ }^{1}$ Occupational Therapy Division, School of Health and Rehabilitation Sciences, The Ohio State University Medical Center, \\ 453 West Tenth Avenue, Suite 406, Columbus, OH 43210, USA \\ ${ }^{2}$ School of Health and Rehabilitation Sciences, The Ohio State University Medical Center, 453 West Tenth Avenue, Suite 406, \\ Columbus, OH 43210, USA \\ Correspondence should be addressed to Stephen J. Page; stephen.page@osumc.edu \\ Received 9 July 2014; Accepted 23 July 2014; Published 12 August 2014 \\ Copyright (C) 2014 Brittany Hand et al. This is an open access article distributed under the Creative Commons Attribution License, \\ which permits unrestricted use, distribution, and reproduction in any medium, provided the original work is properly cited.
}

Figure 1 was inserted twice and Figure 2 was omitted. Below are the correct figures. 


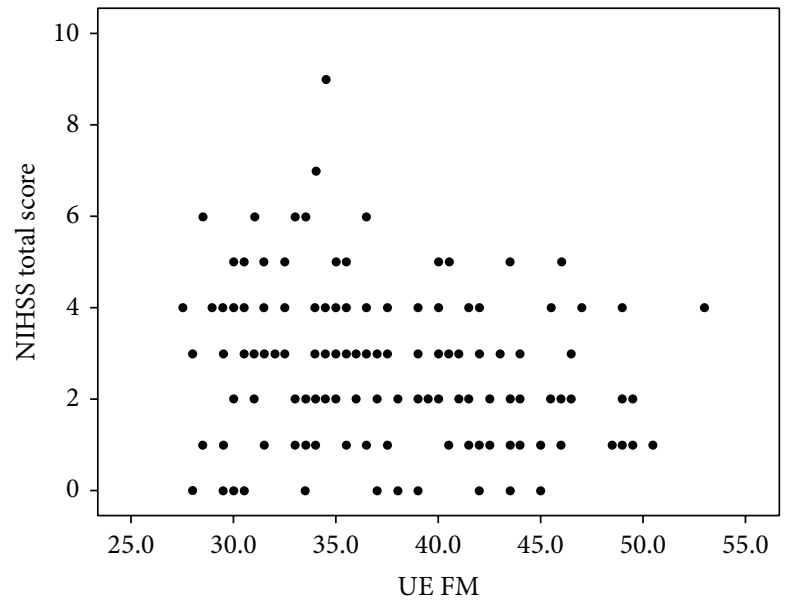

(a)

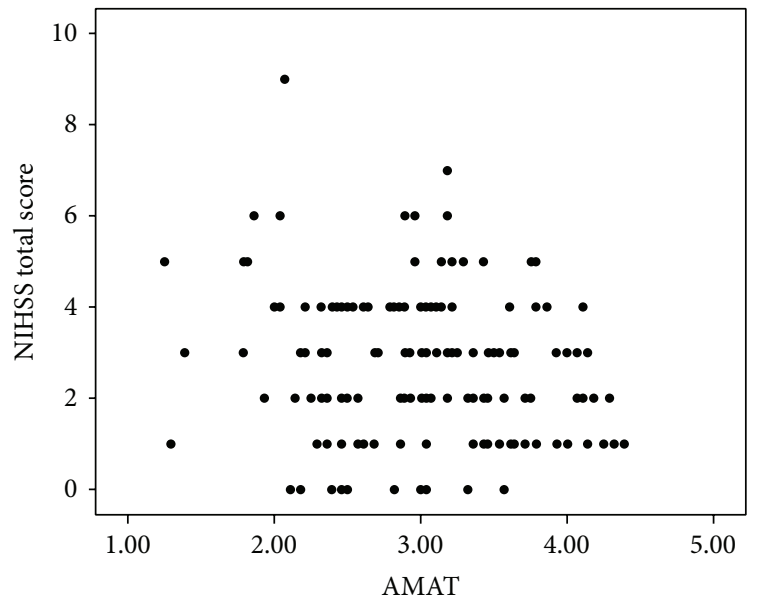

(b)

FIGURE 1: Bivariate plots comparing NIHSS scores with UE FM scores (a) and NIHSS scores with AMAT scores (b).

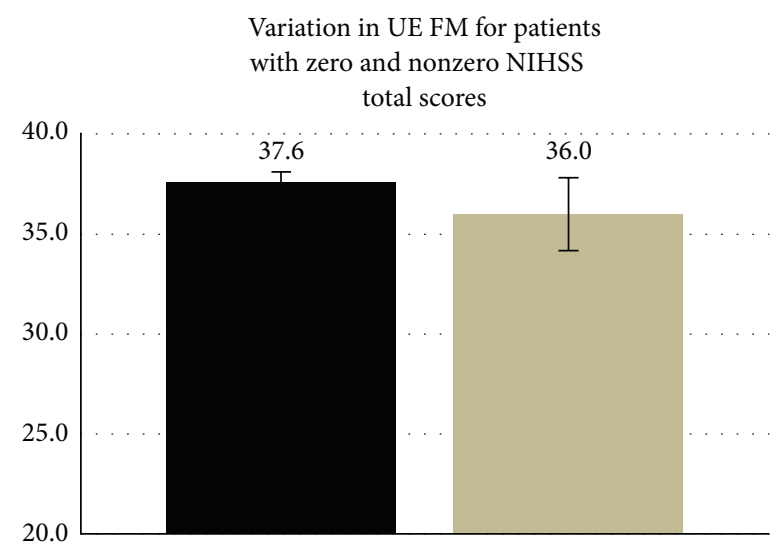

FM-subjects with NIHSS $>0$

FM-subjects with NIHSS $=0$

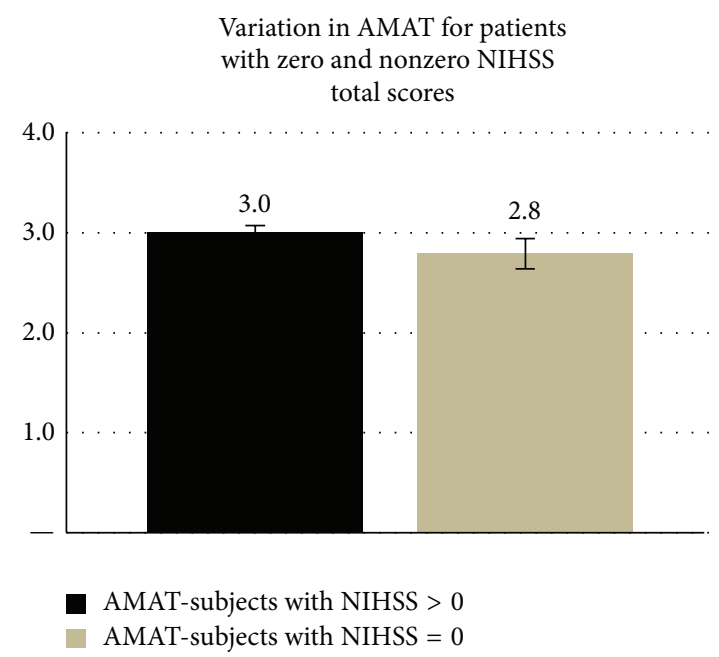

FIGURE 2: Comparison of subjects with zero and nonzero NIHSS scores on the UE FM and on the AMAT. 


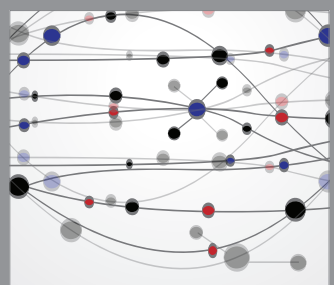

The Scientific World Journal
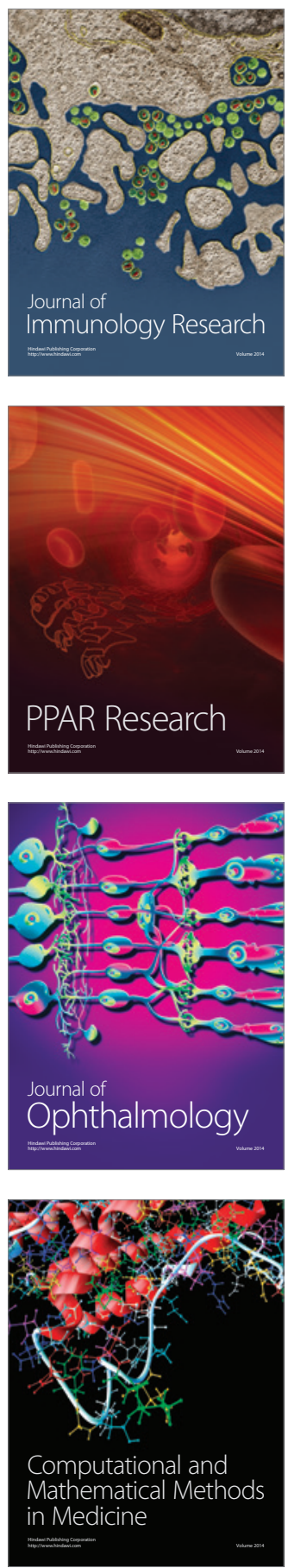

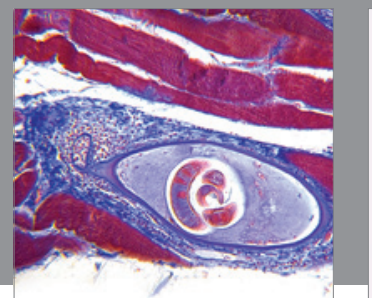

Gastroenterology

Research and Practice
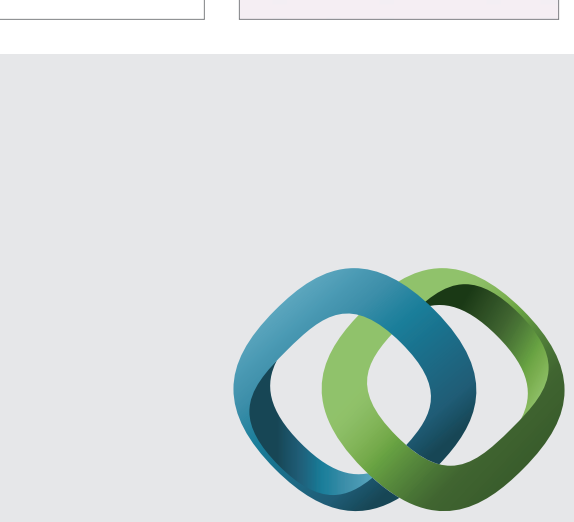

\section{Hindawi}

Submit your manuscripts at

http://www.hindawi.com
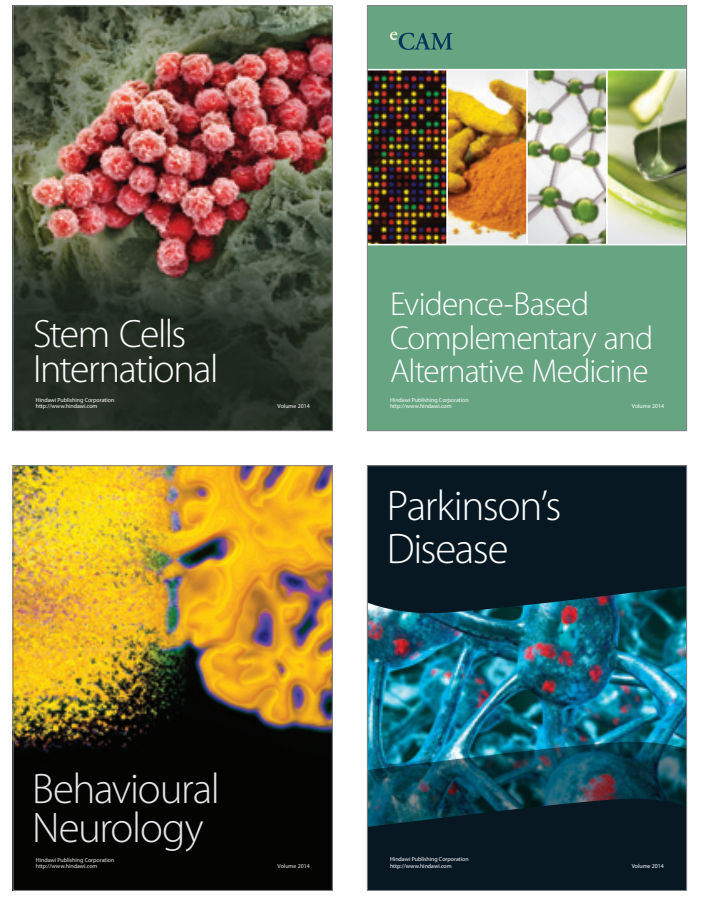
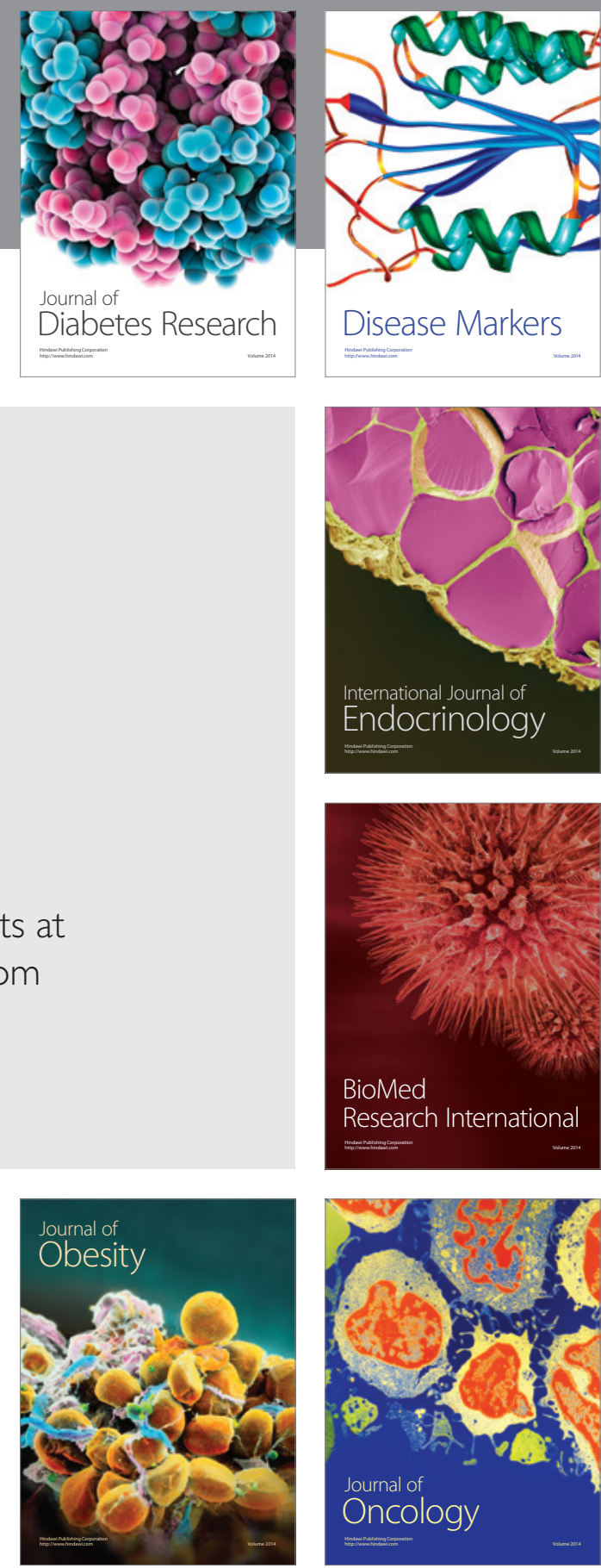

Disease Markers
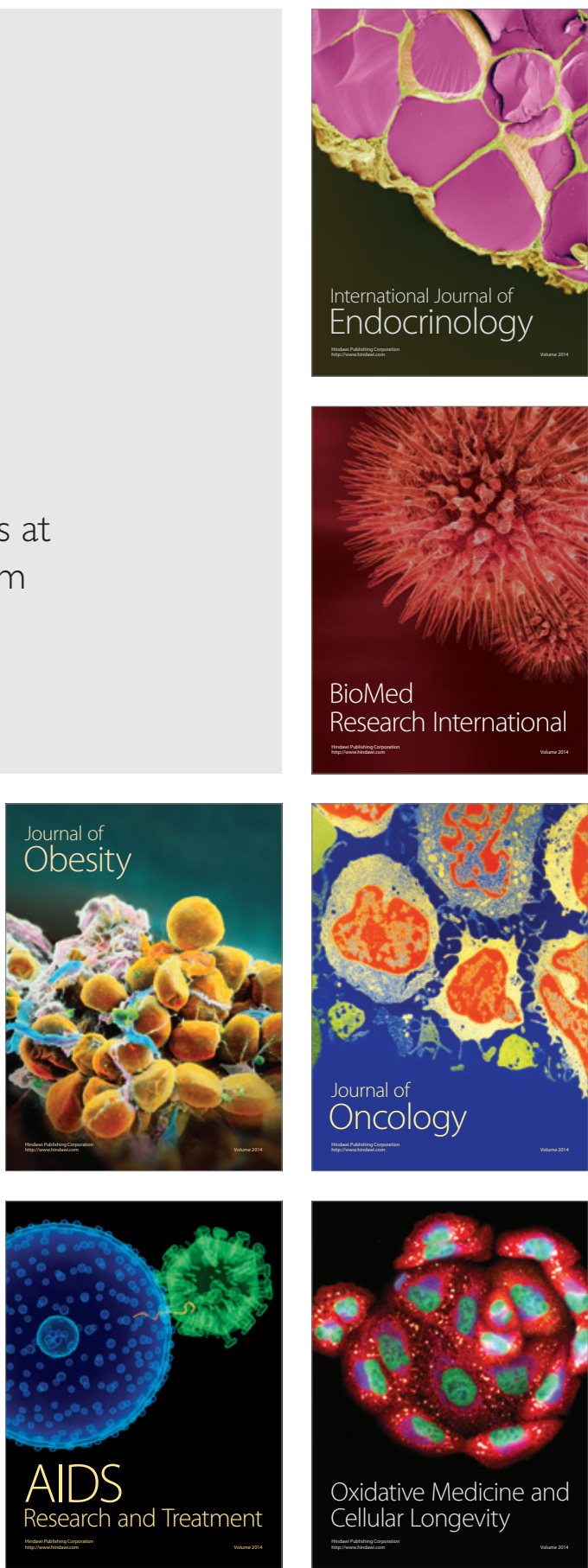